\title{
Pathophysiology and Gastrointestinal Impacts of Parasitic Helminths in Human Being
}

\author{
Firew Admasu Hailu ${ }^{1 *}$, Geremew Tafesse ${ }^{1}$ and Tsion Admasu Hailu ${ }^{2}$ \\ ${ }^{1}$ Dilla University, College of Natural and Computational Sciences, Department of Biology, Dilla, Ethiopia \\ ${ }^{2}$ Addis Ababa Medical and Business College, Addis Ababa, Ethiopia \\ *Corresponding author: Firew Admasu Hailu, Dilla University, College of Natural and Computational Sciences, Department of \\ Biology, Dilla, Ethiopia
}

\begin{abstract}
Introduction: This study mainly focus on the major pathologic manifestations of human gastrointestinal impacts of parasitic worms.

Background: Helminthes and protozoan are human parasites that can infect gastrointestinal tract of humans beings and reside in intestinal wall. Protozoans are one celled microscopic, able to multiply in humans, contributes to their survival, permits serious infections, use one of the four main modes of transmission (direct, fecal-oral, vector-borne, and predator-prey) and also helminthes are necked multicellular organisms, referred as intestinal worms even though not all helminthes reside in intestines. However, in their adult form, helminthes cannot multiply in humans and able to survive in mammalian host for many years due to their ability to manipulate immune response.

Objectives: The objectives of this study is to assess the main pathophysiology and gastrointestinal impacts of parasitic worms in human being.

Methods: Both primary and secondary data were collected using direct observation, books and articles, and also analyzed quantitatively and qualitatively following standard scientific methods.

Results and conclusion: Parasites are organisms living temporarily in or on other organisms called host like human and other animals. Gastrointestinal parasitic helminthes have medical importance and live as endoparasites of human and other animals as host. Such pathogenic parasitic helminths are hookworms (Ancylostoma duodenale and Necator americanus), pinworm (Enterobius vermicularis), roundworm [(Ascaris lumbricoides) and lymphatic filariasis (Wuchereria bancrofti and Brugia timori)], whipworm (Trichuris trichiura), threadworm (Strongyloides stercoralis), heartworms (Dirofilaria immitis), and Guinea worm (Drancunculus medinensis). In addition, intestinal worms can transmit via fecal-oral route, direct contact with infected persons, zoonotic transmission, skin penetration, oral and anal sex, ingestion of contaminated food or water, etc and also factors that promote its transmission includes hot and humid climate, high population density, poor personal hygiene, presence of insects as vectors for carriers of parasites, limited economic resources and some social cultural habits. However, its prevention strategies include use of proper sewage disposal methods, consumption of clean and treated safe drinking water and food, proper hygiene, etc and the main treatment of antihelminthic medications include albendazole, metronidazole, diethylcarbamazine, etc as suggested by physician. Therefore, due to intestinal parasites can be easily transmit and cause great economic, health and social problems, and so prevention methods are greatly advisable.
\end{abstract}

Keywords/phrases: Gastrointestinal Impacts; Parasitic Helminthes; Pathophysiology 


\section{Introduction}

According to zoological sciences, parasitic worms are the most successful invertebrate animals found as parasite (endoparasites and exoparasites of other animals) with varied shape of elongate, threadlike, roundworms, or eelworms. Many of parasitic worm species are extremely successful parasites, their biological process and food availability is largely depend on the appropriate host of animals. Gastrointestinal parasitic worms are multicellular organisms, vermiform invertebrate animal species, almost microscopic, of which are endoparasites of animals (Pokharel, and Larsen [1] and Pokharel et al. [2]). In addition, intestinal parasites infect gastro-intestinal tract of humans such as helminthes and protozoan which live in intestinal wall (Loukopoulos et al. [3]). Protozoans like Entoameba histolytica, and Giardia lamblia are single celled microscopic, able to multiply in humans, which contributes to their survival, cause serious infections (Patel and Khaldekar [4]) and transmit to another human through a fecaloral route (Magambo et al. [5]) and also helminthes are necked multicellular organisms, referred as intestinal worms even though not all helminthes reside in intestines (Markell et al. [6]). Similarly, in their adult form, helminthes cannot multiply in humans and they are able to survive in mammalian host for many years due to their ability to manipulate immune response (Bogitsh et al. [7]).

Economic impact of human gastrointestinal parasites are varied and it depend on the development of the country and lifestyle of the society. Based on American Psychopathological Society (2019), gastrointestinal parasitic worms have great economic impacts on the host animals by causing diseases and feeding other microorganisms. Human intestinal parasitic infections have harmful effect on survival, appetite, growth, physical fitness, school attendance and cognitive performance (Green et al. 2011) and also poor sanitation, clean drinking water scarcity and poor personal hygiene practices may contribute to the rapid spread of intestinal parasite (Celiksoz et al. [8]). Furthermore, environmental factors also play a great role in the frequency of intestinal parasitic infection as hot and humid tropical climate favor increased parasite prevalence (Geiger et al. [9]). In addition, in developing countries, intestinal parasites are widely distributing due to low level of environmental sanitation, contaminated water and unaware of simple health promotion practices such as personal and food hygiene, altitudinal effect, urbanization, irrigation, and country resettlement (Endeshaw, et al. [10]).

Epidemiology of gastrointestinal parasites study in biological sciences indicates, intestinal parasitic infections are the major causes of human disease in most tropical region which estimates about 3.5 billion people in the world are infected, of which about 450 million school aged children's are at high risk (kaizer and Utzinger, [11]). The epidemiology of intestinal parasitic infections shows that, parasites are found in every age group and in both sexes but, the incidence is high in some areas and in some age groups (Abu [12] and Judith et al. [13]). World Health Organization (WHO), large number of people around worldwide infected with some type of intestinal parasite, and amoebiasis, ascariasis, hookworm and trichiuriasis infections are among most common infections of top ten global health problems (CDC [14]) and more than 980 million people are infected by A. lumbricoides (Mengistu et al. [15]). Lymphatic filariasis (LF) are endemic in 72 tropics and sub-tropics countries where about 1.4 billion people are at risk of infection and about 120 million people infected with one or more types of the lymphatic filariae (Rao [16]). The most highly distributed intestinal parasites includes Ascaris lumbricoides, Giardia lamblia, Necator americanus, Ancyclostoma duodenale, Trichuris trichiura, Enterobius vermicular, Wuchereria bancrofti and Brugia timori (Adem [17]) with varying prevalence in different areas. Therefore, collecting relevant information, organizing and brief scientific explanation on the above some example of human pathogenic gastrointestinal parasitic helminths invertebrate animals species is required.

Methods, Pathophysiology and gastrointestinal impacts of helminthes: This article is mainly focus on the pathophysiology and gastrointestinal impacts of various helminthes including their symptoms, transmission, diagnosis, prevention and treatment of intestinal parasitic infections and also their economic impacts on human being. In addition, both primary and secondary data were collected using direct observation, books, articles and from key health personnel (i.e. doctors, health officers, nurses, and laboratory technician) and also the collected statistical data and information were analyzed and interpretation of quantitative data using table and figures, and the qualitative method represents by explanation.

Pathophysiology of intestinal parasitic worms: In biological sciences, pathological information on the main causes and effects of the disease-causing pathogens of some intestinal parasites of human being and some other mammals are explained as follows. Parasitic organisms can be endoparasites or ectoparasites living temporarily inside or on the body of other organisms as host (Adem [17]). The main routes of transmission of some helminthes, protozoa and microsporidia to humans is via the fecal-oral, direct contact with infected persons, zoonotic transmission, ingestion of contaminated food or water and so cause gastrointestinal infections (Xiao [18]) and also there are various ways of infecting and transmission of intestinal parasitic worms such as mosquito bites, ingesting organisms eggs, penetration of the body skin, when fecal matter get into the mouth via contaminated food or water, eating of raw meat containing encysted larvae of helminth species, swimming in contaminated water, oral and anal sex, nonsexual close contact like diaper changing (Capó [19]; CDC [14]). In 
addition, eating of raw meat containing encysted larvae of a species can lead to a disease with two phases called gastrointestinal phase (occur after ingestion of infected meat by humans) and systemic (parenteral) phase (occur when the larvae enter the lymphatic circulation then into the blood, skeletal muscles, myocardium, and brain which are high in oxygen content) (Capó, [19]).

Intestinal parasites are one of the most important causal agents of gastrointestinal disorders like diarrhea, dysentery, vomiting, lack of appetite, hematuria, abdominal distension, loss of weight, abdominal pain, nausea, and Iron deficiency anemia (Even and Stephenson, 2001; Wafa [20]) and also causes itching and scratching around perianal area, swelling of the lower limbs, pharyngeal irritation, cough, dyspepsia, etc. Therefore, spreading of intestinal parasitic infections can be controlled by family planning, protecting personal and environmental hygiene, health education and nutrition and also prevention strategies include use of proper sewage disposal methods, consumption of clean and treated safe drinking water and food, proper hygiene such as hand washing, cleaning fruits and vegetable before consumption (Evan et al. [21])

According to the nature of gastrointestinal parasites, there are various methods of diagnosis and treatments suggested by physicians. These various diagnosis methods of intestinal parasitic infections can be done by morphological examination, host antibody detection, parasite antigen detection, parasite DNA detection, specific antigen detection in stool specimen, rapid diagnostic test, etc (Regnath et al. [22]) and also these infections are among the most widespread of all chronic human infections worldwide (Wafa [20]). There are different methods of treatment modalities for various intestinal parasites, antihelminthic medications include Albendazole, Mebendazole, Pyrantel Pamoate (Ashford, et al. [23], Gupta et al. [24]). The most common treatment for hookworm, pinworm, whipworm, roundworm and other worms are albendazole and/or mebendazole (Bethony, et al. [9]; Avinash and Mollie [25]) and Diethylcarbamazine is an effective microfilaricidal drug (Adinarayanan, et al. [26]).

Human gastrointestinal impacts of helminths (worms): In biological sciences, human parasitic infections are the major medical problem all over the world, especially in developing countries where they cause more morbidity and mortality than other infectious diseases and are the primary cause of death. The two main groups of parasitic organisms are protozoans include plasmodium species and helminths metazoan organisms, include the cestodes, trematodes and nematodes (Gillian, et al. [27]). Parasitic organisms are organisms that can found internal or external body surface of other organisms, can live in a variety of ecological settings and some infections have zoonotic importance as disease producing agents resulting in potentially serious infections (Dickson et al. [28]). There are many pathogenic gastrointestinal parasitic species cause diseases to human being and other animals with various shapes such as elongated, threadlike, roundworms, eelworms active invertebrate animals and helminths species have greatest medical importance (Gaurab [29]). Therefore, some of the most medical importance of pathogenic gastrointestinal parasitic helminths invertebrate animals species such as hookworms (Ancylostoma duodenale and Necator americanus), pinworm (Enterobius vermicularis), roundworm (Ascaris lumbricoides), Lymphatic filariasis (Wuchereria bancrofti and Brugia timori), whipworm (Trichuris trichiura), threadworm (Strongyloides stercoralis), heartworms (Dirofilaria immitis), Guinea worm (Drancunculus medinensis), Entoameba histolytica, and Giardia lamblia are explained briefly as follows.

Hookworm: The hookworm infection is caused by the blood-feeding parasites of the two nematode species known as Ancylostoma duodenale and Necator americanus. Epidemiology of hookworm is estimated that 576-740 million individuals are infected today, of these about 80 million are severely affected (Gasser, et al. [30]) and the morbidity associated with severe infection includes intestinal blood loss, anemia, and protein malnutrition. Hookworms are named because the anterior end curves dorsally, suggesting a hook as indicated in figure 1. The major etiology of Hookworm infection is Necatar Americanus which is found in Americas, sub-Saharan Africa, and Asian countries (Hotez et al. [31]). Both species of hook worms have their ways of transmission, meaning that Necator americanus transmitted only via penetration of skin and Ancylostoma deodenale transmitted in various ways like percutaneously, orally, and probably transplacentally, and early migrations of the larvae cause Wakana disease which characterized by nausea, vomiting, pharyngeal irritation, cough, and dyspepsia (Hotez et al. [32]). In this case, humans are definitive hosts for both Necator americanus and Ancylostoma duodenale and also primarily it infects dogs, but humans can be dead-end hosts that prevent the larvae from completing their life cycle (John et al. [33]).

In addition, the burden of infection that caused by hook worm is concentrated mostly among the world's most poorest people who are living on less than two dollars per day. Of this people, mainly children in low and middle income countries are most vulnerable population as infection with hookworm can inhibit their growth, physical fitness, impair, intellectual and cognitive development (Power and Helen [34]). Based on report of disease information for Hookworm indicates that, hookworm infection has numerous synonyms including acanthocheilonemiasis, ancylostomiasis, necatoriasis, and uncinariasis and also statistics report indicate that, one third of all pregnant women in developing countries are infected with Hookworm, 56\% of all pregnant women in developing countries are suffer from anemia, and $20 \%$ of all maternal deaths are either directly or indirectly related to anemia which caused by hook worms (Gyorkos et al. [35]). 

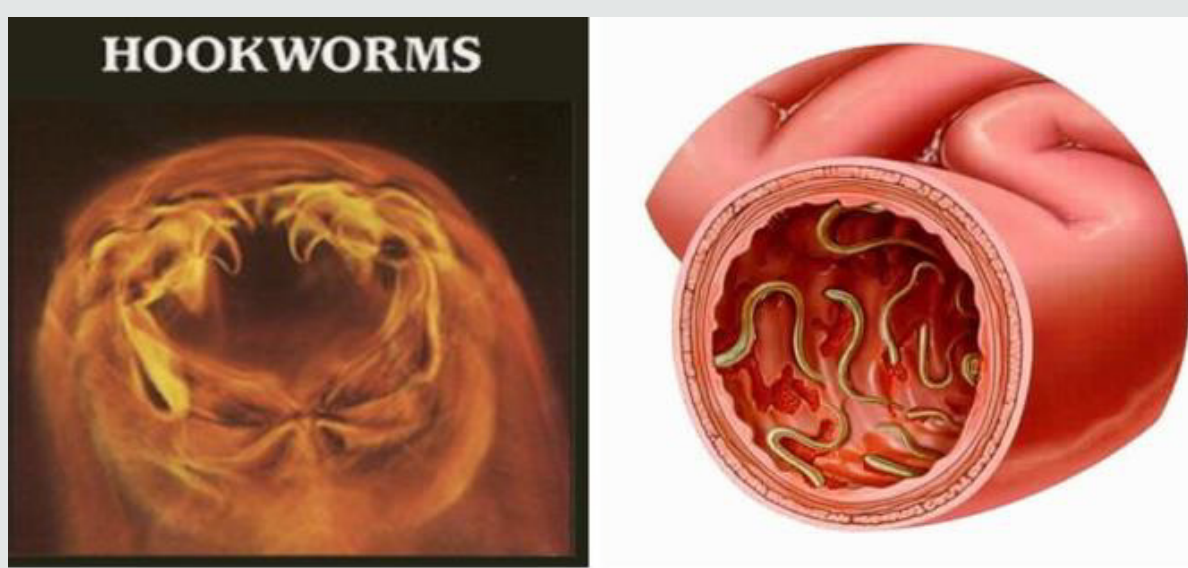

Figure 1: Hookworms structure of the anterior end curves dorsally and its physiological impacts (Gyorkos et al. [35]; Hotez et al. [31]; John et al. [33]).

Pinworm: The pinworm (Enterobius vermicularis) is known as threadworms, is a very common intestinal parasite, and one of the most common nematode infections in the world. The medical condition associated with pinworm infected known as enterobiasis (Judith [36]) and humans are the only natural host for this infection and the transmission occurs in people who are living in most crowded environments and usually within families. In addition, the morphology of pinworm are tiny, thread-like parasite that live in the colon and rectum of infected individuals (Charles [37]), whitish and named after the characteristic pin-like tail present on the posterior part of female worms (Cook [38], Dahlstrom and Macarthur [39]) as indicated in Figure 2 bellow. Similarly, this infection most commonly occurs in children, but any individual is vulnerable and people from tropical climates and school-aged children are the most vulnerable to E. vermicularis infection. However, this infection is caused by ingestion of the pinworm eggs and route of infection spread by ingesting pinworm eggs that have contaminated fingers, bed lines, clothing, nightclothes and most commonly through the fecal-oral route (Wang et al. [40]) and some of the symptoms includes diarrhea, skin irritation, intense, discomfort, and rash around anus and vagina and also a single tablet of mebendazole (Vermox) and albendazole (Albenze) is effective medication. Therefore, protecting personal and environmental hygiene is the most important advisable prevention methods of pinworm infection.

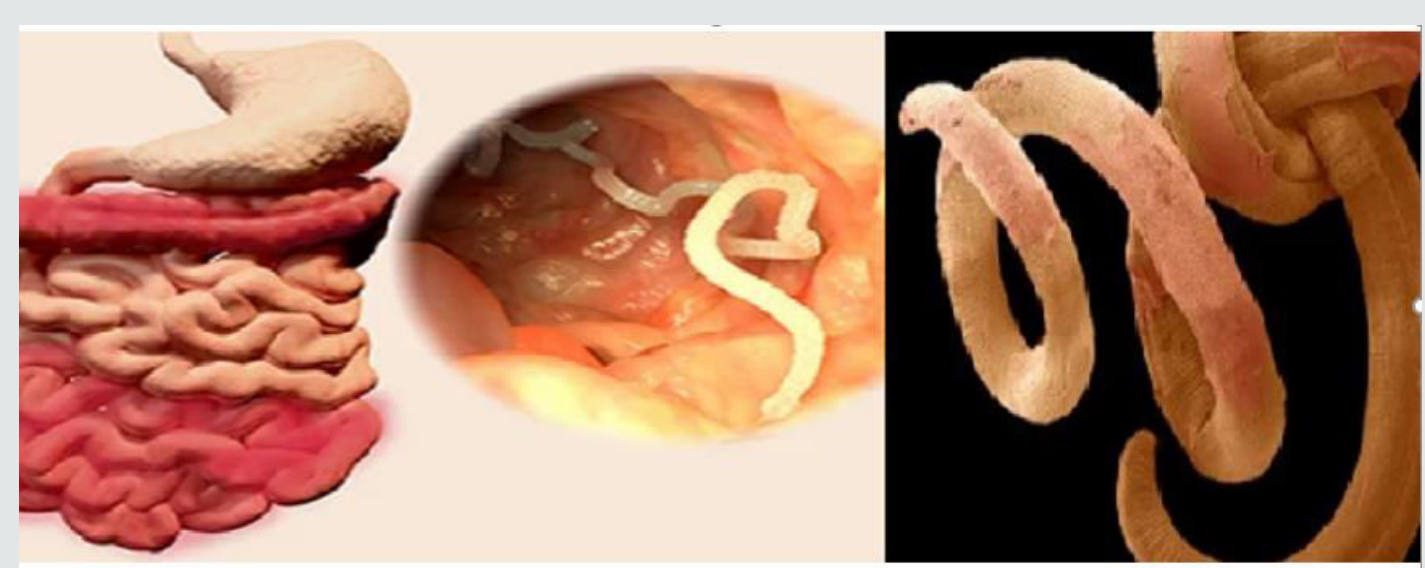

Figure 2: The morphology of pinworm and its living area of colon and rectum (Cook [38], Dahlstrom and Macarthur [39]).

Roundworm: According to World Health Organization (2017), the soil-transmitted helminths infection infects approximately 1.5 billion people in the worldwide, livestock, and wild animals (Eijck and Borgsteede [41]; Nganga et al. [42]). Round worm species known as Ascaris lumbricoides is one of the most common parasitic helminths that infect humans, mainly children as indicated in Figure 3 bellow, that caused by the intestinal roundworm Ascaris lumbricoides which infects approximately 800 million people (Brooker and Pullan [43]). The main transmission of this helminths begins as a female Ascaris can lay 200,000 eggs per day, passing out through the host's feces and in good soil, embryo nation is complete in two weeks. Viable eggs remain after signs of fecal matter have disappeared and the eggs can survive long periods in the soil. Infection begins with the ingestion of embryonated eggs 
containing L3-stage larvae which hatch in the small intestine before penetrating the intestinal wall of the cecum and colon to start their tissue migratory phase (Murrell et al. [44]). These L3-stage larvae then migrate through the liver before reaching the lungs by 6-8 days post-infection (Roepstorff et al. [45]). From the lungs, the larvae are coughed up and swallowed again, thereby reaching the small intestine where the nematodes will further develop into the L4 and adult stages and remain for approximately 1 year (Dold and Holland [46]). Therefore, protecting personal and environmental hygiene is the most important advisable prevention methods of Ascaris lumbricoides infection.
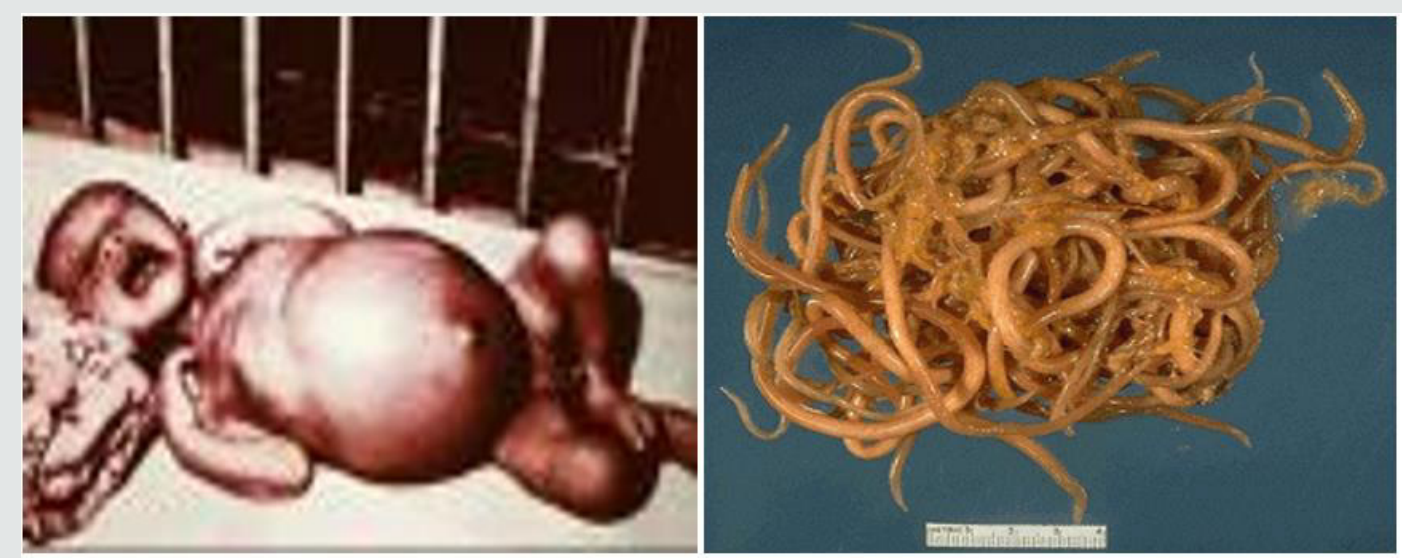

Figure 3: Morphological impacts of Ascaris lumbricoides (Murrell et al. [44]; Roepstorff et al. [45]; Dold and Holland [46]).

Trichnellosis: The round worm nematodes known as Trichinellosis (trichinosis) is a parasitic infection results from the genus and species name of Trichinella spiralis and caused by eating (consuming) of undercooked or improperly cooked or raw meat (usually pork), horse, or meat of other domestic animal and wild game like bear meat, humans can acquire the infection and it infect various organ such as human legs as indicated in Figure 4. The Trichinella spiralis species is the most common cause of human disease by eating raw meat of pork. Although, other mammals like wild carnivores and horses can be reservoirs of infection. Trichinella spiralis can cause various symptoms from the most common fever, abdominal pain, diarrhea, nausea, vomiting, myalgia to the more severe like myocarditis and encephalitis. T. spiralis is a roundworm nematode intestinal parasite (Blaxter et al. [47]) and possesses the capability of infecting a wide range of mammals including pigs, horses, reptiles, and birds but it causes disease only in humans. Similarly, some reports have mentioned an occasional acquisition of the disease by ingestion of reptile meat, including lizards and turtles (Lo et al. [48]), however, there are no reports that indicates human to human transmission. Therefore, in addition to protecting human personal and environmental hygiene, stop eating of undercooked meat of both domestic and wild game animal is the most important advisable prevention methods of Trichinella spiralis and other infection.

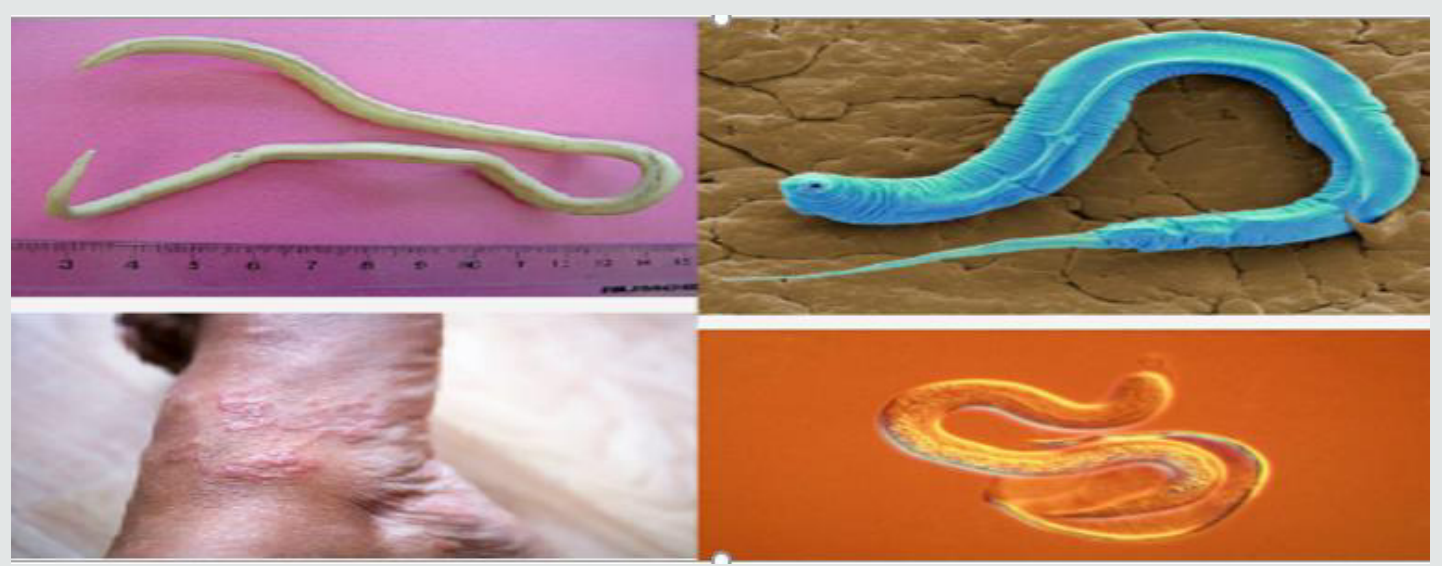

Figure 4: The morphology of Trichinella spiralis and its infection on human leg (Blaxter et al. [47]; Lo et al. [48]).

Whipworm: The whip like worm of Trichuris trichiura also known as the human whipworm, is a roundworm that causes trichuriasis in humans. The morphology of Trichuris trichiura is referred as the whipworm due to it looks a whip like structure with a wide at the posterior end and a narrow anterior esophagus containing a thick posterior anus. In addition, these worms 
are usually pink in color and attach to their host via the slender anterior end and also the size of these worms are varies from 3 to $5 \mathrm{~cm}$. Usually, the female is larger than the male (Truscott et al. [49]) and the females can lay from 2000 to 10,000 eggs per day anywhere which deposited in the soil from human feces. The eggs become mature after 14 to 21 days and enter an infective stage. At this stage, if humans ingest the embryonated eggs, the eggs start to hatch in the human small intestine and utilize the intestinal microflora and nutrients to multiply and grow in the host as indicated in figure 5. The majority of larvae move to the cecum, penetrate the mucosa and mature to adulthood. Infections involving a high-worm burden will typically involve distal parts of the large intestine (Truscott et al. [49]). In addition, Like ascariasis and hookworm infection, Trichuriasis is also soil-transmitted helminthiasis infections; it considered a neglected tropical disease by the World Health Organization (WHO) and Centers for Disease Control and Prevention (CDC). The most common cause of trichuriasis is ingestion of infected eggs that are found in soil. This is often due to poor sanitary conditions, including open defecation and using human feces as fertilizer. Some recent studies show that people with certain chromosome traits may be predisposed or have increased susceptibility to acquiring trichuriasis (Brooker et al. [50]). Therefore, in addition to protecting personal and environmental hygiene, stop ingesting any kind of food before washing hands and uncooked vegetables is the most advisable prevention methods of Trichuris trichiura infection.

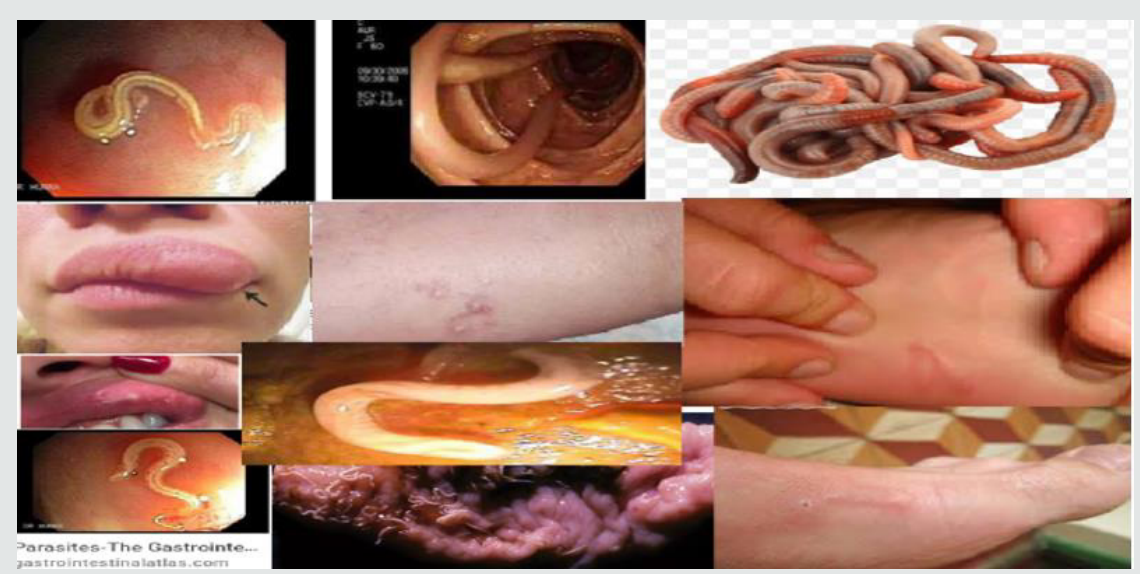

Figure 5: Morphological impacts of Whipworm (Trichuris trichiura) in human body (Brooker et al. [50]; Truscott et al. [49]).

Lymphatic filariasis: Lymphatic filariasis (LF) (elephantiasis) is a neglected tropical disease caused by the filarial nematode parasites. These worms are endemic in 72 countries in the tropics and sub-tropics where more than 1.4 billion people are at risk of infection (WHO, 2009) and about 120 million people are infected with one or more types of lymphatic filariae (WHO, 2009). Filariasis is a parasitic helminthiasis disease caused by an infection with roundworms of the Filarioidea type (Amaral et al. [51]), spread by blood-feeding diptera such as black flies and mosquitoes. In addition, there are eight known filarial nematodes use humans as their definitive hosts and which divided into three groups based on their niche occupy in the host body such as Lymphatic filariasis, Subcutaneous filariasis, and Serous cavity filariasis. Meaning that, the Lymphatic filariasis is caused by Wuchereria bancrofti, Brugia malayi, and Brugia timori worms occupy in the lymphatic system, including lymph nodes and these worms lead to syndrome of elephantiasis. The Subcutaneous filariasis is caused by the eye worm known as Loa loa, Mansonella streptocerca, and Onchocerca volvulus. The Loa loa worms occupy the subcutaneous fat layer of the skin causes Loa loa filariasis, and 0 . volvulus causes river blindness. Serous cavity filariasis is caused by the worms Mansonella perstans and Mansonella ozzardi, occupy the serous abdominal cavity (Amaral et al. [51]).

Morphological impacts of Lymphatic filariasis (elephantiasis) is a condition which characterized by swelling of the lower limbs (legs), male genitalia, arms, or breasts of human as indicated in the following figure 6 . There are three causative agents of lymphatic filariasis in humans, such as Brugia malayi, Wuchereria bancrofti and Brugia timori, but both Wuchereria bancrofti and Brugia timori are differ from B. malayi in morphology, symptom, and geographical degree (Johhn et al. [52]) and B. malayi is transmitted by Mansonia mosquitoes. Lymphatic filariasis is caused by species of nematodes known as Wuchereria bancrofti, Brugia malayi and Brugia timori are transmitted by the bite of a number of mosquito species such as Anopheles, Culex, Mansonia and Ochlerotatus (WHO [53]). When biting infective third stage larvae break out of the mosquito proboscis and enter the skin through the puncture wound and parasite then develops over a period of 6-12 months in the human host. Adult filarial worms exist in the afferent lymphatics close to draining lymph glands and microfilariae of $\mathrm{W}$. bancrofti and B. malayi show the nocturnal periodicity (Nutman [54]) in most endemic areas but either non-periodic or semi-periodic in some others. 


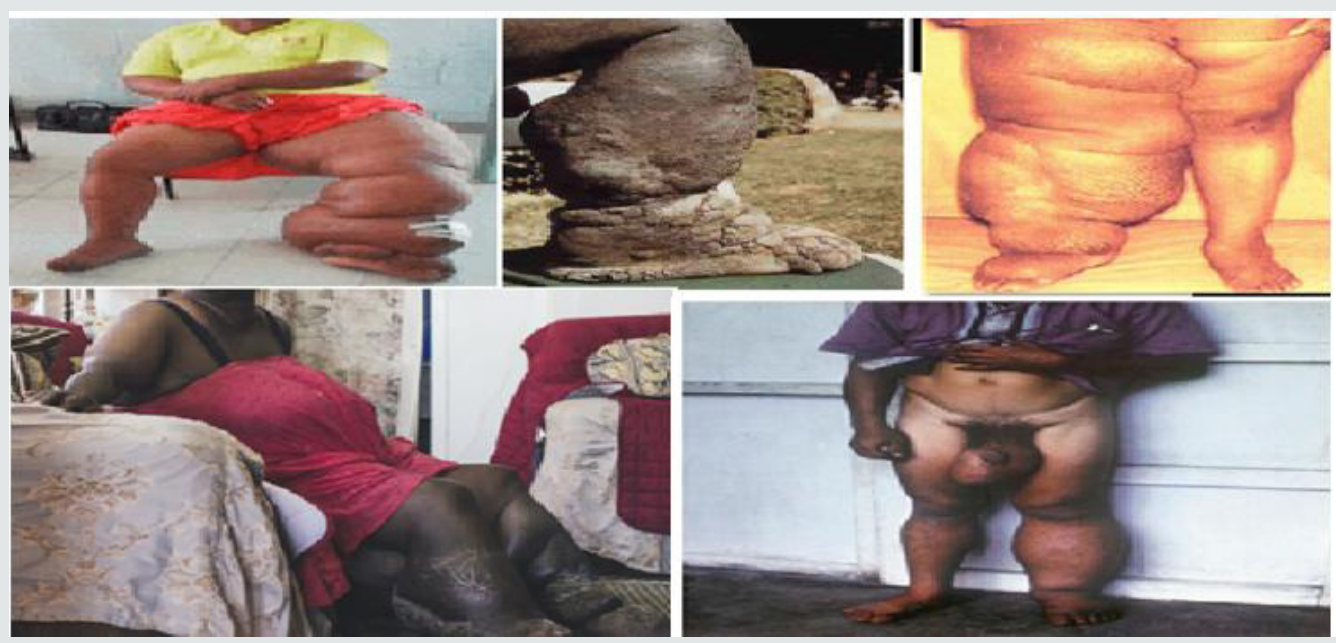

Figure 6: Various physiological impacts of Filarial worms on human being (Casiraghi et al. [55]; Johhn et al. [52]; Choi et al. [56]).

In addition to swelling of the lower limbs, Lymphatic filariasis also cause impairs the lymphatic system and can lead to the abnormal enlargement of body parts, causing pain, severe disability and social stigma. The major pathologic manifestations includes acute fever accompanied by tender swelling of the lymphatics male genitalia leads to dysfunction and swelling of the legs, arms, or breasts of human (Casiraghi et al. [55]; Choi et al. [56]). Chronic swelling of the legs and compromised lymphatic drainage may result in secondary bacterial infections and sclerosis and verrucous changes of the overlying skin. The most severe cases are referred as elephantiasis and the male genital involvement includes hydrocele, funiculitis, epididymitis, and orchitis (Casiraghi et al. [55]; Choi et al. [56]). For example, filarial species can cause lymphatic filariasis in humans and most of the infections are caused by Wuchereria bancrofti and spreads from person to person by the bites of mosquito (Rao [16]). Therefore, a parasitic helminthiasis disease filariasis is caused by an infection with roundworms of the
Filarioidea, transmitted by the bite of black flies, and a number of mosquito species like Anopheles, Culex, Mansonia and Ochlerotatus via blood-feeding with their proboscis, parasite enter via pierce wound skin and then develops in the host and so, prevention methods are highly advisable.

Guinea worm: Adult Guinea worm (Dracunculus medinensis) in knee joint is occurs mainly in Asia and Africa. An adult Guinea worm in humans infection occurs from drinking water containing Cyclops which have been infected by the worm. The worm larvae in the Cyclops hatch out and penetrate the human intestine and the eggs are passed out of the human when a gravid female migrates to the skin and causes an ulcer as indicated in Figure 7. Skin ulcer comes into contact with water the free-swimming larvae are released and this larvae then swim until they are eaten by a Cyclops or die (Peters and Gilles [57]). Therefore, it is very important treating drinking water to protect health of people which caused by drinking contaminated water.

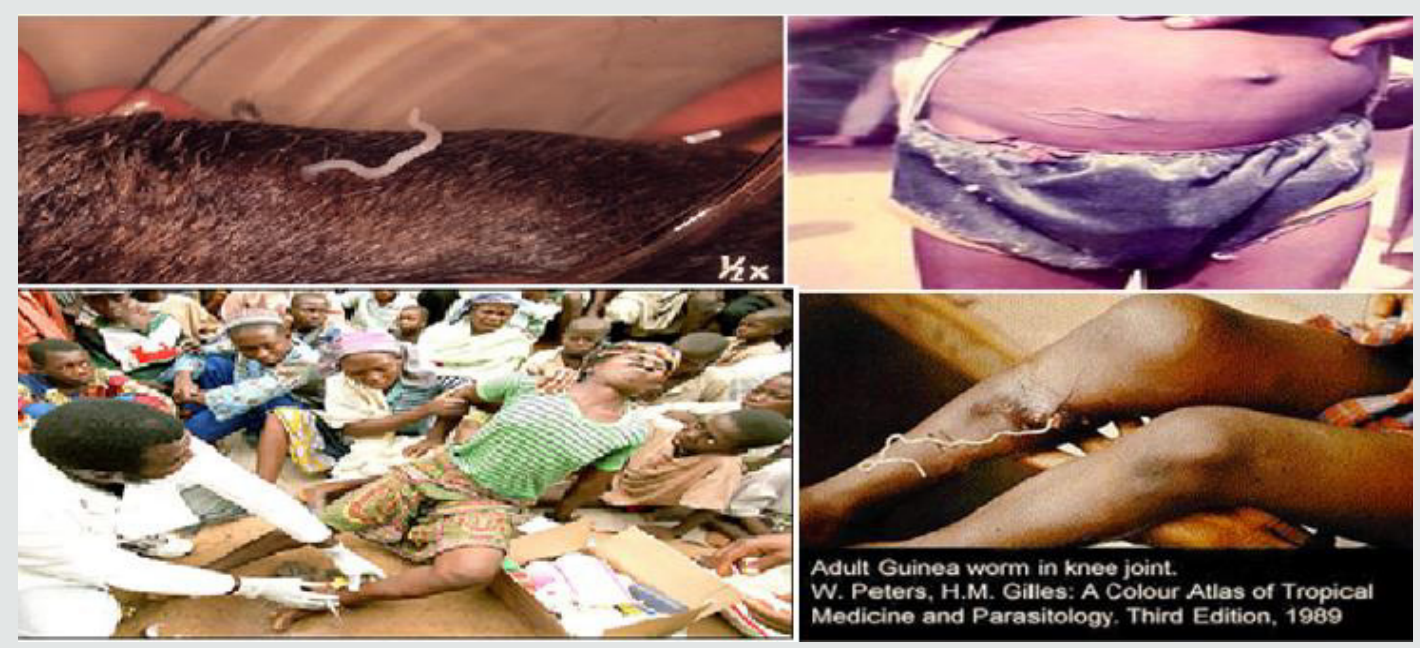

Figure 7: Physiological impacts of Guinea Worm on human (Peters [57]). 
Heartworms: The heartworm (Dirofilaria immitis) is a type of parasitic filarial roundworm, also known as dog heartworm, a small tread-like worm that causes dirofilariasis, spread from host to host through the bites of mosquitoes and rarely infects humans (Amaral et al. [51] CDC [58]). There are four genus of mosquitoes that transmit dirofilariasis, such as Ades, Culex, Anopheles and Mansonia (CDC [58]). The main definitive host is the dog, but it can also infect cat, wolves, coyotes, jackals, foxes, and other animals such as ferrets, bears, seals, sea, lions and under rare circumstance humans (AHS [59]). However, opposing to their name, adult heartworms often reside in the pulmonary arterial system of the lung and the heart as indicated in figure 8 and also damage those vessels and tissues of infected host animals and causes a serious complications for the infected host if untreated eventually leading to death, most often as a result of secondary cognitive heart failure (Ettinger et al. [60]).
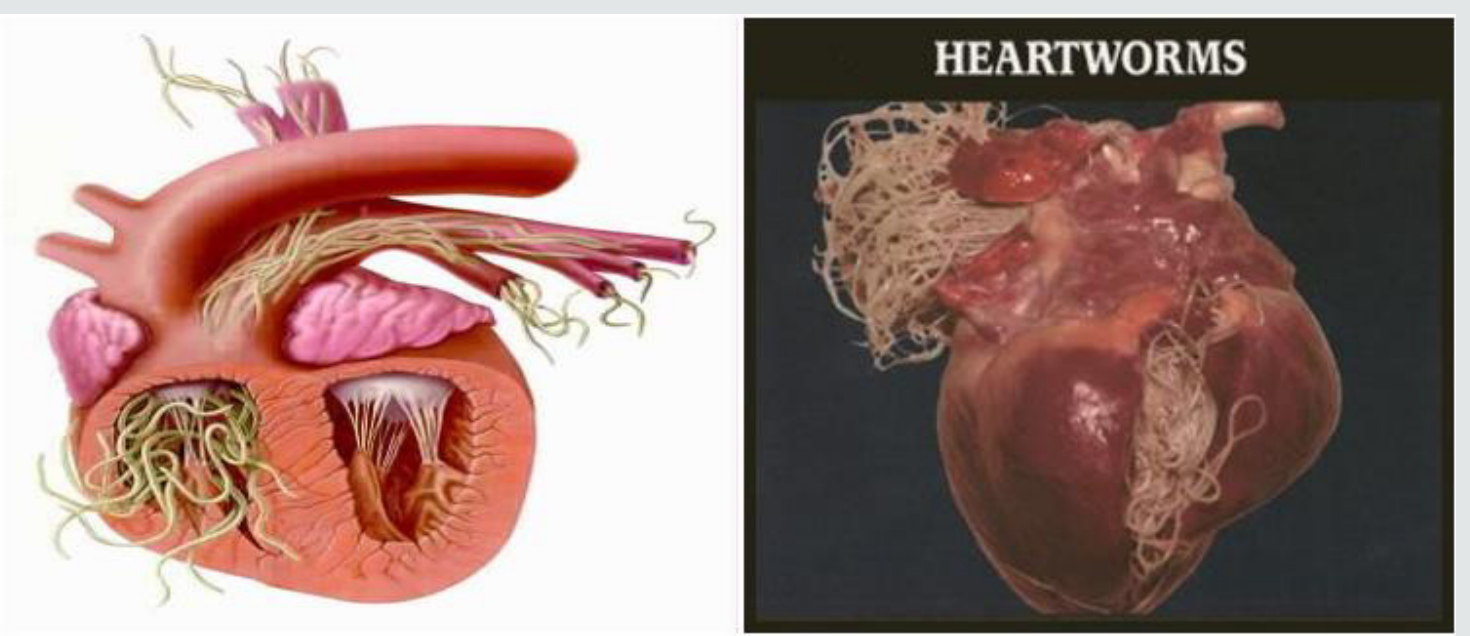

Figure 8: Physiological impacts of the heartworms (Amaral et al. [51]; CDC [58]).

Tapeworms: Tapeworms or cestodes are ubiquitous among humans and animals worldwide. They are unique among all worms because they are perfectly specialized for the parasitic life and are incapable of living independently. Adult cestodiasis is far less pathogenic to human than other helminthic infections, and only heavy infections are able to cause physical damage of the gut wall, and possible blockage of the intestine. However, larval infections of few species of cestodes may cause serious clinical complications as in cysticercoids (Wael [61]). According to CDC [62], the tapeworms are parasites that live in the small intestines of many different animals species, including humans and its size is vary depending on the species, example, while Echinococcus multilocularis is less than $1 \mathrm{~cm}$ long, an adult Taenia saginata up to 10 metres long. Except for the head, a tapeworm's body is made up entirely of small segments, called proglottids, which break off from the end of the worm's tail and both intact proglottids and the eggs may be passed in the feces. Of all the tapeworms in pets, Echinococcus spp. pose the greatest disease risk to people. Tapeworm infection in adult animals rarely causes illness, even with large numbers of worms, but the motile proglottids may cause irritation around the anus, causing the animal to chew or rub the area or "scoot" as indicated in figure 9. There are three main groups of tapeworms, each containing one or more species, that are a concern for most domestic animals and humans. Each group poses a different level of risk to people and may be spread between animals and people in a different way (CDC [62]).

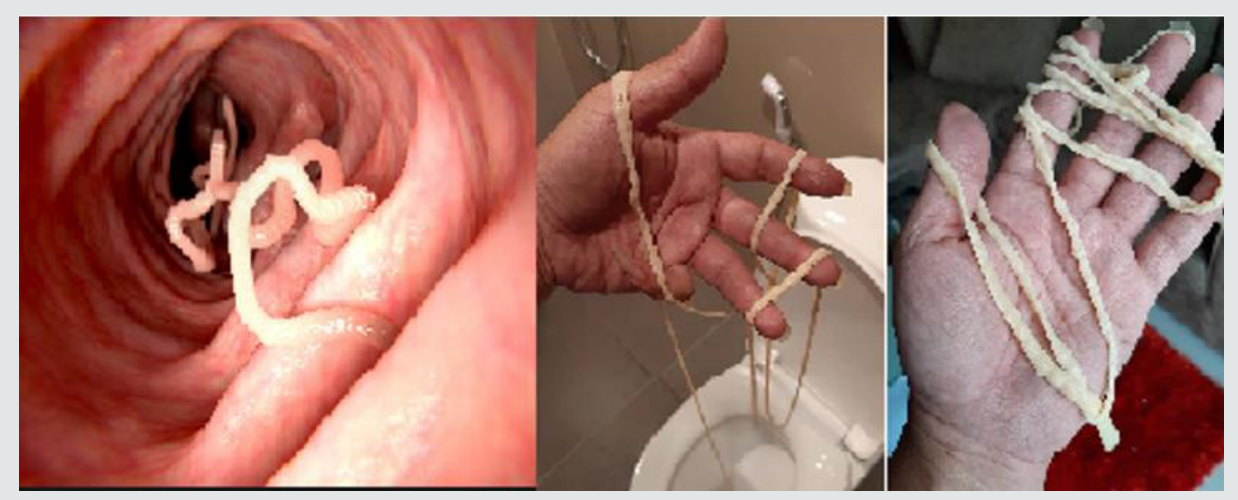

Figure 9: The morphology of tapeworm and its impact on host animals (CDC [62]). 
The Dipylidium caninum is the most common type of tapeworm found in dogs and cats and can be found in pets worldwide. The eggs of D. caninum are passed is an animal's feces, does not make animals or people sick, but it can be uncomfortable because the proglottids shed by the worms can move by themselves, and may get stuck around the anus, causing itching and this infection can cause weight loss in pets but easily treated with oral anti-parasitic drugs. Similarly, human infections with tapeworm of Taenia species have a problem in some areas, come from livestock can cause infection of any kind in people. There are two kinds of Taenia species that can cause infection in humans, these are cysticercosis and taeniasis (intestinal tapeworm infection) as briefly found in Table 1. The main causes of tapeworm in people is eating raw or undercooked beef or pork. The intermediate stage (cysticercosis) of a Taenia tapeworm that infects humans, they must have contact with feces from an infected person. Therefore, taeniasis is common where cattle and pigs meat for human consumption and around poor sanitation. Intestinal tapeworm infections can be easily treated using oral dewormers such as praziquantel and also can be prevented in people using the two major components are preventing intestinal infection in pets and preventing human exposure to the parasite eggs and cysts (CDC [62]).

Table 1: Tapeworm species and its transmission between humans and domestic animals Ref. (CDC [62]).

\begin{tabular}{|c|c|c|c|c|}
\hline Tapeworm group & Tapeworm species & $\begin{array}{c}\text { Definitive host (intestinal } \\
\text { worm) }\end{array}$ & $\begin{array}{l}\text { Intermediate host (cyst } \\
\text { stage) }\end{array}$ & Notes \\
\hline Dipylidium spp & D. caninum & $\begin{array}{c}\text { Dogs } \\
\text { Cats } \\
\text { Humans (rare) }\end{array}$ & Fleas & $\begin{array}{l}\text { Transmitted by swallowing } \\
\text { infected adult flea }\end{array}$ \\
\hline \multirow{3}{*}{ Taenia spp.* } & T. solium & Humans & $\begin{array}{l}\text { Cysticercosis } \\
\text { Pigs } \\
\text { Humans }\end{array}$ & $\begin{array}{l}\text { Intestinal infection from } \\
\text { eating undercooked pork, } \\
\text { cysticercosis from contact } \\
\text { with human sewage }\end{array}$ \\
\hline & T. saginata & Humans & cattle & $\begin{array}{l}\text { Intestinal infection from } \\
\text { eating undercooked beef }\end{array}$ \\
\hline & $\begin{array}{l}\text { T. multiceps } \\
\text { T. crassiceps } \\
\text { T. serials }\end{array}$ & Dogs & $\begin{array}{c}\text { Small prey } \\
\text { Humans (rare) }\end{array}$ & RARE cause of cysticercosis \\
\hline \multirow{2}{*}{ Echinococcus spp. } & E. granulosus & $\begin{array}{c}\text { Wild canids } \\
\text { (especially foxes \& wolves) }\end{array}$ & $\begin{array}{l}\text { Cystic echinococcosis } \\
\text { Humans Medium to large } \\
\text { prey: } \\
\text { Rabbits, sheep, moose }\end{array}$ & \multirow{2}{*}{$\begin{array}{l}\text { Eggs identical to Taenia spp. } \\
\text { Infection in humans is } \\
\text { uncommon or rare in some } \\
\text { areas, but can be extremely } \\
\text { serious. }\end{array}$} \\
\hline & E. multilocularis & $\begin{array}{l}\text { Wild canids (especially } \\
\text { foxes) } \\
\text { Cats }\end{array}$ & $\begin{array}{c}\text { Alveolar echinococcosis } \\
\text { Humans } \\
\text { Small prey } \\
\text { Voles, mice, lemmings }\end{array}$ & \\
\hline
\end{tabular}

\section{Conclusions and Future Directions}

Conclusions: This review article concluded that parasitic infections which caused by helminthes and protozoa are the major causes of human disease in most countries of tropical region and helminthic infections is highly predominant than protozoan infection. Intestinal parasitic infection can affect any individual of human being those who cannot protect their environment and personal hygiene including hand washing and shortening fingernails [63-65]. Therefore, improvement of personal and environmental hygiene is very important to prevent from infecting by those intestinal parasites. Because both hook worms (Ancylostoma duodenale and Necator americanus) species can transmit via skin penetration, percutaneously, orally, probably transplacentally, etc. In addition, people who are living in most crowded environments from tropical climates are the most vulnerable to species of pinworm (Enterobius vermicularis), and round worm (Ascaris lumbricoides) infection which caused by ingestion of its eggs mostly through the fecal-oral route and so, protecting personal and environmental hygiene is important to prevent hook worms, pinworm and round worm infection. Similarly, the Trichinella spiralis species is the most common disease in human which caused by eating raw meat of pork and bear meat. Helminthiasis, like Ascariasis and hookworm infection, Trichuriasis is also soil-transmitted infections, which caused by ingestion of infected eggs due to poor sanitary environment. Therefore, personal and environmental hygiene, stop ingesting uncooked meat and vegetables is advisable prevention methods.

The pathogenic helminthiasis filarial parasites are affecting millions of people, especially those living in tropical countries, and may cause significant dermatologic manifestations and caused by an infection with roundworms of the Filarioidea, transmitted by the bite of black flies and mosquito species such as Anopheles, Culex, Mansonia and Ochlerotatus with their proboscis via bloodfeeding. Similarly, infection of Guinea worm occurs in humans while drinking Cyclops containing water which have larvae hatch out then penetrate the human intestine, the eggs passed out, migrates 
to the skin and causes an ulcer. Therefore, removing stagnant water to protect filarial reproduction habitat and to protect from drinking by human being and also health workers with government should focus on this regards and others prevention methods are advisable. Generally, helminthiasis in most instances associated with stunting of linear growth, physical fitness and low educational achievement due to their immune systems are not yet fully developed habitually play in fecally contaminated soil. Therefore, helminthiasis can cause gastrointestinal and other diseases in human, and various economic impacts and so it can be prevented by protecting personal and environmental hygiene, stop eating of undercooked meat of both domestic and wild game animal, stop ingesting uncooked vegetables with unwashed hands, stop drinking of not treated or unclear water, etc are advisable prevention methods.

Future Directions: Most of intestinal parasitic infections are mainly cause from poor personal and environmental hygiene including ingesting parasitic eggs with unwashed hands, drinking unclear water, eating of raw meat, skin penetration, etc. Therefore, new research will require with multidisciplinary collaboration to enable the integration of traditional practices with new ideas created by the scientists and more research required on nematode biology and the environment, and nematologists must consider several possibilities regarding to how nematode life cycles can be interrupted, how microbial activity at the root soil interface nematode invasion can be promoted, identification of harmful nematodes, selection of resistant varieties, or tolerate nematode infestation, and that can produce acceptable yields and also developing biological control methods are some of the recommended information. In addition, the human pathogenic parasitic filarial helminths are affecting millions of world people, especially those who are living in tropical countries. So, respective nongovernmental and governmental organizations should focus on health and environmental studies that required on creating awareness how to remove sluggish water to prevent filarial reproduction and how to treat drinking water to protect health of people which caused by drinking contaminated water and others best prevention methods are needed to control socio-economic impacts that caused by such gastrointestinal parasites.

\section{References}

1. Pokharel RR and HJ Larsen (2007) The importance and management of phytoparasitic nematodes in western Colorado fruit orchards. Journal of Nematlogy 39: p.96.

2. Pokharel RRHJ Larsen, B Hammon, T Gourd, M Bartolo (2009) Plant parasitic nematodes, soil and root health in Colorado onion fields. In: Godin, R. (ed.). Western Colorado Research Center, Colorado State University. Annual report TR 09-12:39-44.

3. Loukopoulos P, Komnenou A, Papadopoulos E, Psychas V (2007) Lethal Ozolaimus megatyphlon infection in a green iguana. Journal of Zoo and Wildlife Medicine 38: 131-134.

4. Patel PK, Khandekar R (2006) Intestinal parasitic infections among school children of the Dhahira Region of Oman. Saudi Medical J 27: 627 632.
5. Markell EK, John, DT, Krotoshi, WA (2000) Markell and Voges Medical Parasitlogy. Philadephia, WB Sounders 9: 234-239.

6. Magambo JK, Zeyhle E, Wachira TM (2000) Prevalence of intestinal parasite among children in Southern Sudan. East Africa Medical J 15: 288-290.

7. Bogitsh D, Burton J, Carter E, Oelmann N (2012) General characteristics of Nematode Human parasitology. Uk Academic press 15: 269-345.

8. Celiksoz A, Guler N, Guiler G, Oztop AY (2005) Prevalence of intestinal parasite in three socio-economically different regions of Sivas, Turkey. J health popul Nutr 23: 184-1891.

9. Bethony, Brooker, Albonico, Geiger, Loukas, et al. (2006) Soil-transmitted helminth infections: ascariasis, trichuriasis, and hookworm. Lancet 367: $152-1532$.

10. Endeshaw T, Mohamed HM, Tilahun W (2004) Cryptosporidium parvum and other intestinal parasites among diarrheal patients referred to EHNRI in Ethiopia. Ethiop Med J 42(3):195-198.

11. Kaizer J, Utzinger J (2010) The drugs we have and the drug we need against major helminthes Infections. Adv Parasitol 73: 197-230.

12. Abu Mourad (2004) Palestinian refugee conditions associated with intestinal parasitic infection and diarrhea. Nuseirat refugee camp as a case of study. Journal of Public Health 118: 131-142.

13. Judith VM, Helen N, James, TO (2010) The in cadence of, intensity and host morbidity of Human parasitic protozoa infections in: gastrointestinal disorder outpatient in Buea sub Division, Cameroon. J infections Dev Ctries 4: 38-43.

14. CDC (2011) Communicable disease control (CDC). Human Diseases and Conditions.

15. Mengistu A, Gebere Selassie S, Kassa T (2007) Prevalence of intestinal parasitic infections among urban dwellers in southwest Ethiopia. Ethiop J Health Dev 21(1):12-17.

16. Rao R U (2005) "Endosymbiotic Wolbachia of parasitic filarial nematodes as drug targets". The Indian Journal of Medical Research 122 (3): 199-204.

17. Adem M CW (2006) Parasitology for medical laboratory students, $2^{\text {nd }}$ edition edn (Addis Ababa publisher).

18. Xiao L (2010) Molecular epidemiology of cryptosporidiosis: An update. Experimental Parasitology 124: 80-89.

19. Capó V, Despommier DD (1996) Clinical aspects of infection with Trichinella spp. Clin Microbiol Rev Jan 9(1): 47-54.

20. Wafa AI (2010) Intestinal parasite infection among immunocompromised patient in Riyadh, Saudi Arabia. Paki J Biol Sci 13: 390-394.

21. Evans JR, hall KL, Warford, J (2003) Shattuck healths are in the developing world: problems of scarcity and choice. N Engl J med 305: 1117-1127.

22. Regnath T, Klemm T, Ignatius R (2006) Rapid and accurate detection of G.lamblia and Cryptosporidium spp. antigens in human fecal specimens by new commercially available qualitative immunochromatographic assay. J Clin Microbiol Infect Dis. 25: 807-809.

23. Ashford RW, Hart CA, Williams RG (1988) Enterobius vermicularis infection in a children's ward. J Hosp Infect.12(3): 221-224.

24. Gupta YK, Gupta M, Aneja s, Kohli K (2004) Current drug therapy of protozoal diarrhea. Indian J Pediatric 71: 55-58.

25. Avinash Viswanath, Mollie Williams (2019) Trichuris Trichiura (Whipworm, Roundworm)

26. Adinarayanan S, CritchleyJ, Das PK, Gelband H(2007) Diethylcarbamazine (DEC)-medicated salt for community-based control of lymphatic filariasis. Cochrane Database of Systematic Reviews (1): CD003758. 
27. Gillian Stepek, David J Buttle, Ian R Duce, and Jerzy M Behnke (2006) Human gastrointestinal nematode infections. Int J Exp Pathol 87(5): 325-341.

28. Dickson D Despommier, Peter J Hotez (2012) Principles and Practice of Pediatric Infectious Diseases (Fourth Edition).

29. Gaurab Karki (2019) Role of nematodes in Agriculture: Importance of nematodes in soil.

30. Gasser, Cantacessi, Campbell (2009) Improved molecular diagnostic tools for human hookworms. Expert Rev Mol Diagn 9(1):17-21.

31. Hotez P, Bethony J, Bottazzi ME, Brooker S, Buss P (2005) Hookworm: "The Great Infection of Mankind". PLoS Med 2(3): e67.

32. Hotez Peter J, Simon Brooker, Jeffrey M Bethony, et al. (2004) "Current concepts: hookworm infection." The New England Journal of Medicine 351: 799-807.

33. John, David T and William A Petri, Jr Markell and Voge's (2006) Medical Parasitology: Ninth Edition. St. Louis: Saunders Elsevier.

34. Power Helen J (2002) "History of hookworm." Encyclopedia of Life Sciences. John Wiley \& Sons, Ltd.

35. Gyorkos, Larocque, Casapia, Gotuzzo (2006) Lack of Risk Adverse Birth Outcomes After Deworming in Pregnant Women. Pediatric Infectious Disease Journal 25(9): 791-794.

36. Judith Marcin MD (2017) Medical Review on pinworm.

37. Charles Patrick Davis (2019) Pinworm Symptoms, Treatments, and Medication. MD, PhD.

38. Cook GC (1994) Enterobius vermicularis infection. Gut 35(9): 11591162.

39. Dahlstrom JE, Macarthur EB (1994) Enterobius vermicularis: a possible cause of symptoms resembling appendicitis. Aust N Z J Surg 64(10): 692-694.

40. Wang S, Yao Z, Hou Y, Wang D, Zhang H, et al. (2016) Prevalence of Enterobius vermicularis among preschool children in 2003 and 2013 in Xinxiang city, Henan province, Central China. Parasite23: p.30.

41. Eijck I A, Borgsteede F H (2005) A survey of gastrointestinal pig parasites on free-range, organic and conventional pig farms in The Netherlands. Vet Res Commun 29: 407-414.

42. Nganga CJ, Karanja DN, Mutune MN (2008) The prevalence of gastrointestinal helminth infections in pigs in Kenya. Trop Anim Health Prod 40: 331-334

43. Brooker SJ, Pullan RL (2013) Chapter 13 - Ascaris lumbricoides and ascariasis: estimating numbers infected and burden of disease in Ascaris: The Neglected Parasite, ed Holland C, editor. (Amsterdam: Elsevier;): 343-362.

44. Murrell KD, Eriksen L, Nansen P, Slotved HC, Rasmussen T (1997) Ascaris suum: a revision of its early migratory path and implications for human ascariasis. J Parasitol. 83: 255-260.

45. Roepstorff A, Eriksen L, Slotved HC, Nansen P (1997) Experimental Ascaris suum infection in the pig: worm population kinetics following single inoculations with three doses of infective eggs. Parasitology 115: 443-452.

46. Dold C, Holland CV (2011) Ascaris and ascariasis. Microbes Infect 13 632-637.
47. Blaxter ML, De Ley P, Garey JR, Liu LX, Scheldeman P, et al. (1998) A molecular evolutionary framework for the phylum Nematoda. Nature. 392(6671): 71-75.

48. Lo YC, Hung CC, Lai CS, Wu Z, Nagano I, et al. (2009) Human trichinosis after consumption of soft-shelled turtles, Taiwan. Emerging Infect Dis 15(12): 2056-2058.

49. Truscott JE, Turner HC, Anderson RM (2015) What impact will the achievement of the current WHO targets for anthelmintic treatment coverage in children have on the intensity of soil transmitted helminth infections? Parasit Vectors 8: pp. 551.

50. Brooker SJ, Mwandawiro CS, Halliday KE, Njenga SM, Mcharo C, et al. (2015) Interrupting transmission of soil-transmitted helminths: a study protocol for cluster randomised trials evaluating alternative treatment strategies and delivery systems in Kenya. Randomized Controlled Trial 5(10): e008950.

51. Amaral F, Dreyer, G, Figueredo Silva J, Noroes J, Cavalcnati A, et al. (1994) Live adult worms detected by ultrasonography in human bancroftian filariasis. Am J Trop Med Hyg 50: 753-757.

52. Johhn David T, and William A Petri (2006) Markell and Voge's Medical Parasitology. $9^{\text {th }}$ ed. St. Louis: Saunders Elsevier.

53. WHO (2002) Defining the roles of vector control and xeno-monitoring in the Global Programme to Eliminate Lymphatic Filariasis. World Health Organization, Geneva.

54. Nutman TB (2000) Lymphatic filariasis. Imperial College Press, London.

55. Maurizio Casiraghi, Odile Bain, Ricardo Guerrero, Coralie Martin, Vanessa Pocacqua, et al. (2004) Mapping the presence of Wolbachia pipientis on the phylogeny of filarial nematodes: evidence for symbiont loss during evolution. International journal for parasitology 34: 191-203.

56. Young Jun Choi, Elodie Ghedin, Matthew Berriman, Jacqueline McQuillan, Nancy Holroyd, et al. (2011) A deep sequencing approach to comparatively analyze the transcriptome of lifecycle stages of the filarial worm, Brugia malayi. PLoS Negl Trop Dis. 5: e1409.

57. Peters W, Gilles HM (1989) A color Atlas of Tropical Medicine and Parasitology. Third Edition.

58. CDC (2019) Prevention Centers for Disease Control.

59. American Heartworm Society (AHS) (2014). Heartwormsociety.org.

60. Ettinger, Stephen J, Feldman, Edward C (2010) Textbook of Veterinary internal medicine $\left(7^{\text {th }}\right.$ ed.) WB Saunders Company.

61. Wael Lotfy (2013) Tapeworms and Human Health. Medical research institute, Alexandria University, Egypt.

62. CDC (2013) Worm and germ blogs.

63. Even Ac, staphenson LS (2000) Note by drugs alone the fight against parasitic helminthes. world Health forum 16: 258-261.

64.Geiger SM, Loukes A, Diemert D (2006) Soil transmitted helmets infections: Asciasis. Trachnriasis and hook worm. Lancet 367: 15211532.

65. Green, Hks Sousz BA, Betson M, Batereine NB (2011) Anaciz in Ugndtn preschool children. The relative contribution of intestinal parasitic and malaria parasite. Journal of Public Health 138: 1534-1545. 


\section{(c) $(\oplus$ \\ This work is licensed under Creative Commons Attribution 4.0 License}

To Submit Your Article Click Here:

Submit Article

DOI: 10.32474/RRHOAJ.2020.06.000226

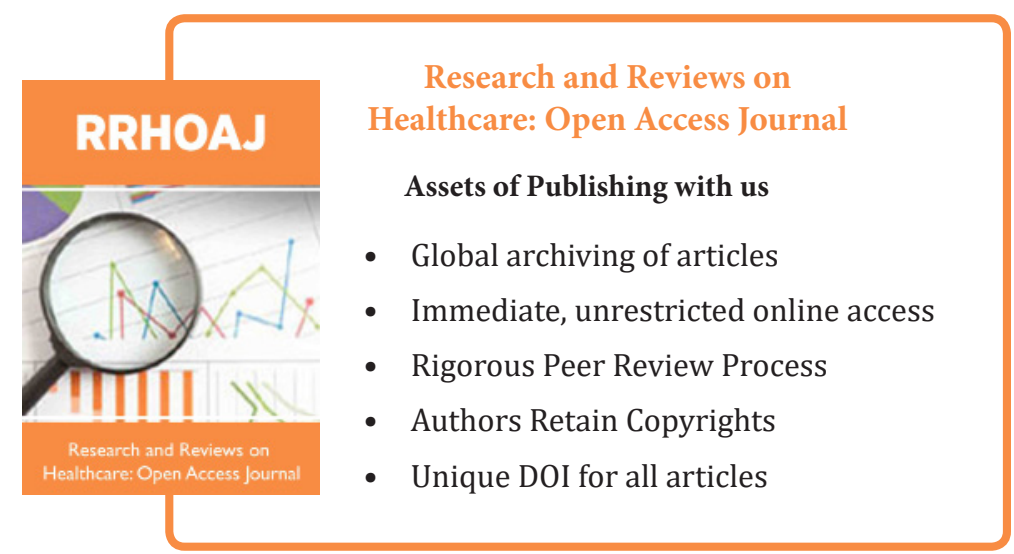

